\title{
Factors associated with using alternative sources of primary care: a cross-sectional study
}

\author{
Charlie Reed ${ }^{1 *}$, Felicia A. Rabito ${ }^{1}$, Derek Werthmann', Shannon Smith and John C. Carlson²
}

\begin{abstract}
Background: Mobile (MHCs), Community (CHCs), and School-based health clinics (SBHCs) are understudied alternative sources of health care delivery used to provide more accessible primary care to disenfranchised populations. However, providing access does not guarantee utilization. This study explored the utilization of these alternative sources of health care and assessed factors associated with residential segregation that may influence their utilization.

Methods: A cross-sectional study design assessed the associations between travel distance, perceived quality of care, satisfaction-adjusted distance (SAD) and patient utilization of alternative health care clinics. Adults $(n=165)$, child caregivers $(n=124)$, and adult caregivers $(n=7)$ residing in New Orleans, Louisiana between 2014 and 2015 were conveniently sampled. Data were obtained via face-to face interviews using standardized questionnaires and geospatial data geocoded using GIS mapping tools. Multivariate regression models were used to predict alternative care utilization.
\end{abstract}

Results: Overall 49.4\% of respondents reported ever using a MCH, CHC, or SBHC. Travel distance was not significantly associated with using either $\mathrm{MCH}, \mathrm{CHC}$, or $\mathrm{SBHC}(\mathrm{OR}=0.91,0.74-1.11 p>.05)$. Controlling for covariates, higher perceived quality of care $(O R=1.02,1.01-1.04 p<.01)$ and lower $S A D(O R=0.81,0.73-0.91 p<.01)$ were significantly associated with utilization.

Conclusions: Provision of primary care via alternative health clinics may overcome some barriers to care but have yet to be fully integrated as regular sources of care. Perceived quality and mixed-methods measures are useful indicators of access to care. Future health delivery research is needed to understand the multiple mechanisms by which residential segregation influences health-seeking behavior.

Keywords: Access, Utilization, Racial/ethnic disparities, Distance, Perceived quality, Primary care, GIS

\section{Background}

Use of primary care services significantly reduces chronic disease morbidity. Adults in the U.S. who report seeing a primary care physician have lower odds of premature death and lower personal medical costs than those who report seeing specialists for their care [1]. Underutilization of primary care services is predominantly experienced in minority and low socioeconomic populations, two groups subject to high rates of chronic conditions [2, 3]. This is

\footnotetext{
*Correspondence: Charles.reed@mt.gov

${ }^{1}$ Tulane School Public Health and Tropical Medicine, 1440 Canal St, New Orleans, LA 70112, USA

Full list of author information is available at the end of the article
}

likely because these groups experience more barriers to accessing health services than other populations $[4,5]$. Identifying and removing these barriers to access is critical to improving the health status of racially-marginalized and socially disadvantaged individuals.

Preliminary research suggests that residential segregation is a prominent barrier to accessing primary care [6-10]. Across the U.S., the odds of having a primary care physician shortage were 67\% higher in majority African American zip codes than in zip codes with a White majority and the difference increased with increasing degree of segregation [8]. Geographic inaccessibility, primarily defined as distance, has been highlighted as a key mechanism by which 
residential segregation limits access [6, 8-10]. Establishing primary care clinics in minority neighborhoods has been shown to improve geographic access and subsequently increase utilization [10].

Among individuals living in segregated neighborhoods, the impact of geographic distance on access may be complicated by an individual's perception of the quality of care available to them. As a result of segregation, minority individuals experience constrained social networks and a proliferation of medical mistrust, perceived discrimination, and perceptions of poor clinic quality [8]. These are additional barriers that make people less likely to seek and use primary care services that would otherwise be considered accessible [7, 11-13]. Additionally, people are known to travel farther in order to receive care from a doctor of their own race $[14,15]$. Given this information, it appears that travel distance is important but subjective and that additional factors should be considered in order to more accurately identify the drivers of underutilization.

Community (CHCs), mobile (MHCs), and schoolbased health clinics (SBHCs) are community-based alternatives to traditional primary care. Their goal is to provide more geographically accessible care in trusted and less stigmatized settings [16-20]. Persistent barriers to traditional primary care sources suggest that alternative health care settings may have an important role to play in reducing health disparities by providing more accessible care. These alternative sources of health care are not typically studied as a health system. The goal of this study was to explore the extent to which MHCs, CHCs, and SBHCs are utilized by marginalized populations and to assess the factors associated with geographic residential segregation that influence their utilization.

\section{Methods}

\section{Study setting and study population}

The study was conducted in New Orleans, Louisiana where a long history of residential segregation continues to this day [21, 22]. Based on 2010 U.S. Census data, New Orleans ranks 32nd among Metropolitan areas for degree of residential segregation. Following the devastation of Hurricane Katrina in 2005, the New Orleans primary care system was decentralized with an emphasis on addressing racial and income differences in geographic access to care [23, 24]. A prominent feature of the reorganized health system was the integration of $\mathrm{CHCs}$ (including Federally-Qualified Health Centers), MHCs, and SBHCs in underserved communities. The new system reached an estimated $80 \%$ of the low-income population of the Greater New Orleans (GNO) area in 2012 [24, 25].

To obtain information about the extent to which $\mathrm{CHCs}$, MHCs, and SBHCs are utilized, the factors that are associated with their use, and how these alternative forms of health care delivery are perceived by the community they are designed to serve, a convenience sample of 299 individuals was surveyed between August 2014 and December 2015. Eligible participants included adults (age $\geq 18$ ), caregivers of children aged 5-17, and caregivers of adults who resided in New Orleans and who spoke Spanish or English.

\section{Data collection}

Data were collected at community health fairs held throughout low-income and minority neighborhoods in the GNO area and during home visits as part of an ongoing asthma study targeting the same population. New Orleans' health fairs are tabled by many organizations engaged in improving quality of life within the community. During the fairs, a table was staffed by trained researchers to provide and assist respondents the survey questionnaire. Participants were also recruited from an on-going asthma study. For these individuals the survey questionnaire was completed in their home. The 57-item questionnaire (Additional file 1), included socio-demographic characteristics, perceptions of $\mathrm{CHC}$, MHCs, SBHCs, barriers to care, usual source of health care, presence of chronic diseases, connectivity of care, and health care utilization. All responses were self-reported. The survey instrument was pilot tested prior to its use and informed consent was obtained prior to any data collection. The study was approved by the Tulane University Biomedical Institutional Review Board. A detailed description of survey components follows.

\section{Geographic access}

Geographic access was measured by mapping the shortest network distance (miles) via Orleans, Jefferson, and St. Bernard Parish (County) roads between the participant's reported home address and the nearest eligible clinic (CHCs, MHCs, or SBHCs). Data were geocoded using ArcMap software version 10.2 (ESRI, 2011 Redlands CA). Home addresses outside of any of the 3 included parishes were excluded from the study. If an individual provided a street name but no house number, the midpoint of the street was used as the home address. A list of primary clinics active in 2014 was obtained from the Louisiana Public Health Institute. Clinics included $31 \mathrm{CHCs}, 14$ pediatric clinics ( $\mathrm{PCHCs}$ ), $4 \mathrm{MHCs}$, and 6 SBHCs. Adult and caregivers of adults were considered eligible to receive service from $\mathrm{CHCs}$ and MHCs, while children were considered eligible for PCHCs, MHCs, and SBHCs. Neither multiple buffer zones nor Euclidean distances were used to determine 
geographic access because network travel distance is considered a more precise representation [26-28].

\section{Perceptions of clinic quality and barriers to care}

Study participant's perceptions of alternative types of primary care clinics (CHCs, MHCs, SBHCs) was assessed using 20 questions from the Barriers to Care Questionnaire (BCQ). The reliability and validity of the BCQ has been established in previous studies [29]. The BCQ quantifies the "circumstances that may interfere with accessing or using care in low-income populations" $[30,31]$. The BCQ is comprised of four subscales. The Pragmatics subscale measures logistical and cost issues that might prevent or delay appropriate utilization of a clinic. The Skills subscale measures the respondent's perceptions of the acquired or learned strategies that are needed to navigate through, manipulate, or function competently within the health care system. The Expectations subscale measures the expectation that, if used, an individual will receive poor quality of care, and the Marginalization subscale measures the internalization and personalization of negative experiences within the health care system [30]. Participants answered questions for each clinic type, regardless of whether or not they had ever received services from that type of clinic. The tool was developed to score responses on a scale from 0 (item perceived to be a big problem) to 4 (not a problem at all) and then multiplied by 25 to generate a more communicable 0-100 scale; higher scores indicate fewer perceived barriers to care and higher perceived quality [29]. The survey generates a total score between 0 and 100 which is the calculated average across the average scores of the four subscales.

\section{Perceptions of quality of care and distance: mixed- methods measure}

The absolute distance to a health clinic may be an inadequate predictor of clinic utilization [14, 32, 33]. The Satisfaction-Adjusted Distance (SAD) index was developed by Kwan \& Hawthorne as a mixed-methods measure and alternative indicator [34]. The SAD index accounts for perceived quality of care and geographic distance simultaneously by adjusting travel distance by an individual's perception of the clinic [34]. Perceived distance measures like SAD are novel but have been found to be useful in mapping multi-factorial concepts of the built environment [33, 35-37]. In the current study, BCQ score was substituted for the patientsatisfaction questionnaire score used in the development of SAD [34]. Both questionnaires measure similar domains (trust, interaction, skills, accessibility) using Likert scales with near identical score ranges (0-100 and 1-100 respectively). A lower than average
BCQ score adds to the mapped travel distance, using the equation below.

$$
\begin{aligned}
\mathrm{SAD}= & {[0.1 *(\text { Mean } \mathrm{BCQ}-\text { Individual } \mathrm{BCQ})] } \\
& + \text { Travel Distance }
\end{aligned}
$$

Separate equations were used to calculate adult and child scores. The SAD is presented as a continuous variable in all analyses. A higher SAD indicates less perceived access to care due to a combination of the perception of poor clinic quality and longer travel distances.

\section{Clinic utilization}

The outcome variable in all models was clinic utilization. Adults and caregivers of adult dependents were considered utilizers if they answered 'yes' to having ever used a $\mathrm{MCH}$ or a $\mathrm{CHC}$. Child dependent caregivers were considered utilizers if they answered 'yes' to having ever used a $\mathrm{CHC}$, a $\mathrm{MCH}$, or a SBHC. Non-users for both groups answered 'no' to using any of the eligible clinics.

\section{Statistical analysis}

Means and standard deviations are presented for continuous variables and the number and proportions are presented for categorical variables. The outcome variable, clinic utilization, was dichotomized in all analyses. Bivariate logistic regressions were performed to examine the independent relationship between clinic utilization and three indicators of perceived access (geographic distance, BCQ score, and SAD). Covariates, including the respondent (adult/adult responding for a child), gender, presence of a chronic condition (yes/no), insurance status, and measures of continuity of care; length of time visiting a place for care (No place, $0-3,4-7,8$ or more years), and the length of time visiting a person for care (No person, $0-3,4-7,8$ or more years), were considered as possible confounding variables. Any variable found to be significantly associated $(p<0.05)$ with clinic utilization in bivariate analyses was included in multivariate models to control for potential confounding. The primary exposure variables, BCQ score, travel distance, and SAD index were modeled separately. Unadjusted and adjusted odds ratios (OR) with 95\% confidence intervals (CI) are presented to identify significant predictors of utilization. Correlation and linear regression analyses were performed between SAD index and its two components; $\mathrm{BCQ}$ total score, and travel distance. Median BCQ subscales, stratified by clinic type and whether the respondent had ever used the clinic, are presented to explore barriers by specific clinic type. All analyses were performed with SAS statistical software version 9.4 (SAS Institute, Inc. Cary, North Carolina); two-sided tests were assumed and $p$-values $<0.05$ were considered statistically significant. 


\section{Results}

A total of 299 individuals completed the survey. Due to the low number of respondents $(n=7)$, caregivers of adult dependents were excluded from the analysis resulting in a sample size of 292. Most individuals were sampled from seven locations in Orleans Parish that hosted reoccurring health fairs. Two hundred and seventy-five survey respondents provided their home address and 256 (93.1\%) were successfully geocoded. Of 55 clinics identified, all but two (96\%) were successfully geocoded. Nineteen home addresses were not geocoded, including 15 not located within the Greater New Orleans area, three $\mathrm{P}$. O boxes, and one car.

Characteristics of the study population, stratified by type of respondent, are presented in Table 1 . The majority of respondents were African American (84.4\%), female (67.0\%) and between the ages of 40 and 64 years. Approximately $57 \%$ reported health care access information for themselves while the remaining responded on behalf of the child in their care. The high proportion of people with insurance was a surprise. The majority of adults $(53.9 \%)$ reported having private health insurance while most children (80.2\%) reported coverage through Medicaid.

Respondents had a stable residential history reporting, on average, living 10.4 years at their current address. Continuity of health care was also unexpectantly high; $87.3 \%$ of respondents reported receiving health care at the same location for between 1 and 7 years. Notably, continuity of care was higher for the place where health care was received than for the specific provider of their care. Nine percent of individuals lacked a specific provider for care, compared to $3.7 \%$ lacking a place for care. The proportion of respondents reporting no regular health care provider was more than double the proportion reporting no regular place of care.

Perceived access to care for general health needs was high $(90.4 \%)$. Chronic conditions were common in both children and adults with approximately one-third of all adults and children reporting currently having a chronic condition. Allergies was the most prevalent condition among children $(n=49)$ and hypertension or high blood pressure was the most prevalent condition among adults $(n=22)$ (data not presented). Overall, of those with a chronic condition, $87.7 \%$ reported having access to health care for their specific condition. Perceived access to care for children with a chronic condition was high with $97 \%$ reporting having access to specialized care. Overall, private clinics were the most common place for respondents to receive care and community clinics were the second most common source of care. The type of clinic used differed between adults and children; $85.8 \%$ of children received care in private clinics while $51.9 \%$ of adults received care from private clinics. Adults answering for themselves averaged higher perceptions of quality (69.1) than adults answering for children (62.9).

Overall, use of either $\mathrm{CHCs}, \mathrm{MHCs}$, or SBHS was high; $49.4 \%$ of all respondents reported using either a $\mathrm{CHC}$, $\mathrm{MHC}$ or SBHC. The proportion of adults who reported ever using one of the three types of clinics was considerably higher $(62.0 \%)$ than the proportion of children (33.3\%). Community clinics were the most frequently used source $(76.3 \%)$ compared to $40.9 \%$ using a $\mathrm{MHC}$ and $39.5 \%$ using a SBHC.

The average travel distance from home to the nearest clinic was 1.72 miles. The farthest travel distance to either a $\mathrm{CHC}, \mathrm{MCH}$, or SBHC was 5.76 miles. Schoolbased clinics (median 56.67) had the lowest perceived quality followed by MHC (61.04) and CHCs (64.79). Perceived quality was significantly higher among those who had used the clinic compared to those who had not (data not shown). As shown in Table 2, pragmatic issues presented the greatest barrier to receiving quality care followed by feelings of marginalization. The greatest pragmatic issues (median $<75$ ), consistent across clinic type, were "receiving care after hours or weekends" and "time spent waiting to be seen." For MHC and SBHCs "having to take off work" was a prominent barrier. "Getting to care" did not score as a noteworthy pragmatic barrier for any clinic (median > 75). Among the marginalization items, "not knowing what to expect from one visit to the next" and "doctors rushing patients through the visit" were ubiquitous barriers. "Feeling that doctors provided as little service as possible" was also a barrier for $\mathrm{MCH}$ and SBHCs.

When travel distance was adjusted for patient satisfaction using the SAD index, the average travel distance to a clinic was perceived to be 1.79 miles and the farthest perceived distance was 9.68. Compared to caregivers answering for children, adults had a shorter average travel distance to the nearest clinic (1.4 vs. 2.0 miles) and lower average SAD score (1.2 vs. 2.4).

Table 3 presents the bivariate association between predictors of access to health care and utilization. Higher perceived quality, measured by total BCQ score, was significantly associated (OR 1.02; 95\% CI 1.01-1.04) with increased utilization. Higher SAD score (indicating less perceived access) was negatively associated (OR 0.81; 95\% CI 0.73-0.91) with utilization. Travel distance, measured in miles, was not independently associated with clinic utilization $(\mathrm{OR}=0.91,95 \%$ CI $0.74-1.11)$. The type of respondent (adult vs. child caregiver), insurance status, the length of time having visited one place, and having the same provider were all significantly associated with clinic utilization.

The results of multivariable regression models are presented in Table 4. Both perceived quality $(\mathrm{aOR}=1.02$, 95\% CI 1.01-1.04) and SAD $(\mathrm{aOR}=0.84,95 \%$ CI $0.74-$ 
Table 1 Population Characteristics

\begin{tabular}{|c|c|c|}
\hline \multirow[t]{2}{*}{ Characteristics $(N=292)$} & \multicolumn{2}{|c|}{$\begin{array}{l}\text { Type of Respondent } \\
\text { n (column \%) }\end{array}$} \\
\hline & Adult & Adult for Child \\
\hline \multicolumn{3}{|l|}{ Race/Ethnicity $n=289$} \\
\hline African American & $131(79.4)$ & $113(91.1)$ \\
\hline Other & 34 (20.6) & $11(8.9)$ \\
\hline \multicolumn{3}{|l|}{ Gender $n=285$} \\
\hline Female & $131(79.9)$ & $60(49.6)$ \\
\hline \multicolumn{3}{|l|}{ Age in years $n=281$} \\
\hline$<18$ & - & $125(100.0)$ \\
\hline $18-39$ & $46(29.5)$ & - \\
\hline $40-64$ & $88(56.4)$ & - \\
\hline$\geq 65$ & $22(14.1)$ & - \\
\hline
\end{tabular}

Type of Insurance $n=258$

$\begin{array}{lll}\text { Medicaid } & 19(13.4) & 93(80.2) \\ \text { Medicare } & 20(14.1) & 3(2.6) \\ \text { Private } & 91(64.1) & 20(17.2) \\ \text { Uninsured } & 12(8.5) & 0(0.0) \\ \text { Years living at current address } n=270 & \\ 0-2 & 35(23.2) & 53(44.5) \\ 2-4 & 17(11.3) & 34(28.6) \\ 4-12 & 36(23.8) & 29(24.4) \\ >12 & 63(41.7) & 3(2.5)\end{array}$

Time visiting a specific health facility, $n=267$

$\begin{array}{lll}\text { No regular Doctor/Nurse } & 8(5.4) & 2(1.7) \\ 0-3 \text { Years } & 63(42.6) & 42(35.3) \\ 4-7 \text { Years } & 52(35.1) & 69(58.0) \\ >8 \text { years } & 25(16.9) & 6(5.0)\end{array}$

Time visiting a specific health care provider, $\mathrm{n}=267$

$\begin{array}{lll}\text { No regular Doctor/Nurse } & 21(14.0) & 4(3.4) \\ 0-3 \text { Years } & 67(44.7) & 38(32.2) \\ 4-7 \text { Years } & 39(26.0) & 69(58.5) \\ >8 \text { years } & 23(15.3) & 7(5.9)\end{array}$

Chronic condition $n=255$

$\begin{array}{lll}\text { No Chronic Condition } & 39(26.7) & 24(22.0) \\ \text { Any Chronic Condition } & 107(73.3) & 85(78.0)\end{array}$

Perceive access for chronic conditions $n=194$

$\begin{array}{lll}\text { Access } & 91(84.3) & 79(91.9) \\ \text { No/Incomplete Access } & 17(15.7) & 7(8.1) \\ \begin{array}{l}\text { Perceive General Access } n=280 \\ \text { Access }\end{array} & 138(85.7) & 115(96.6) \\ \text { No Access } & 23(14.3) & 4(3.4) \\ \begin{array}{l}\text { Usual Source of Care } n=278 \\ \text { Private }\end{array} & \\ \text { Other } & 82(51.9) & 103(85.8) \\ & 58(36.7) & 16(13.3)\end{array}$

Table 1 Population Characteristics (Continued)

\begin{tabular}{llll}
\hline Characteristics $(N=292)$ & \multicolumn{2}{l}{$\begin{array}{l}\text { Type of Respondent } \\
\text { n (column \%) }\end{array}$} \\
\cline { 2 - 3 } & \multicolumn{1}{l}{ Adult } & Adult for Child \\
\hline None/ER & $18(11.4)$ & $1(0.9)$ & \\
Utilization of any 3 clinic subtypes $\mathrm{n}=267$ & & \\
Used a clinic & $93(62.0)$ & $39(33.3)$ & \\
Have not used a clinic & $57(38.0)$ & $78(66.7)$ & \\
Continuous Covariates & Statistic & & \\
& Median & SD & Range \\
Time at current address (years) & 4.00 & 13.80 & 80.04 \\
Travel Distance (miles) & 1.30 & 1.28 & 5.67 \\
BCQ Total Score & 64.76 & 22.72 & 87.29 \\
Satisfaction-adj. Distance & 1.94 & 2.56 & 12.75 \\
\hline
\end{tabular}

0.96) remained significant predictors of utilization in models adjusted for insurance status, adult or caregiver respondents, length of visit place and person. Both BCQ and travel distance accounted for a significant proportion of the variance in SAD, 74.7 and $24.9 \%$ respectively (data not presented).

\section{Discussion}

This study sought to explore the extent to which MHCs, $\mathrm{CHCs}$, and SBHCs are utilized by the populations for which they were designed to serve and to assess the factors associated with geographic residential segregation that influence their utilization. Approximately half of the surveyed respondents had used a community, mobile, or school-based clinic, personally or as an accompanying caregiver. Perceptions of clinic quality and satisfactionadjusted distance were statistically significant predictors of clinic utilization, while geographic distance to a clinic was not. The high frequency of care utilization in our study was consistent with other studies that indicate an overall improvement of the New Orleans health care landscape since Hurricane Katrina [24, 38]. However, most survey respondents sought regular care at a private clinic. There were surprisingly high proportions of individuals with private insurance coverage and good continuity of care amongst our sample. Collectively, this evidence suggests that use of $\mathrm{CHCs}$, MHCs, and SBHCs may be more intermittent and unexpected in nature, filling gaps in care that traditional sources cannot. More studies are needed to explore these findings.

Travel distance, though not a significant predictor of utilization, was still an important component of access. Research shows that in some cases distance fails to conceptualize the burden of travel that should be included in the definition of geographic access. Limited access to a motor vehicle, chronic illness, and familial responsibilities all increase the burden of travel and are 
Table 2 BCQ score by Subscale and Clinic Type

\begin{tabular}{llll}
\hline $\begin{array}{llll}\text { BCQ Scale* } \\
(n=280)\end{array}$ & \multicolumn{3}{l}{ Clinic Type } \\
\cline { 2 - 4 } & Mobile & Community & School-based \\
\hline Pragmatics & 58.33 & 58.33 & 54.17 \\
Skills & 66.67 & 66.67 & 58.33 \\
Marginalization & 55.00 & 63.75 & 55.00 \\
Expectations & 66.67 & 75.00 & 58.33 \\
Total** & 61.04 & 64.79 & 56.67 \\
\hline
\end{tabular}

* BCQ scored on scale $0-100$, higher scores indicate greater perceived quality ** Total Score is calculated as an average across all subscales negatively associated with health care utilization and access $[39,40]$. Racial disparities in travel burdens are also well-documented [41]. For example, $20 \%$ of New Orleans households do not own a car, and these households are concentrated in low-income and minority neighborhoods [42, 43]. Because distance does not capture these sentiments, it alone is not a complete measure of accessibility among marginalized populations.

Individuals who perceived an alternative clinics to be of higher quality were significantly more likely to have used a clinic than those who perceived them to be of lower quality. Feelings of marginalization was usually the lowest scoring subscale of the BCQ (second lowest for $\mathrm{CHCs}$ ). It is evident that distance misrepresents racialized spaces as fixed at home. Social networks constrained by residential

Table 3 Bivariate Analyses of health care utilization

\begin{tabular}{|c|c|c|c|c|}
\hline \multirow{2}{*}{$\begin{array}{l}\text { Covariates } \\
N=224\end{array}$} & \multicolumn{4}{|l|}{ Utilization } \\
\hline & $\begin{array}{l}\text { Used } \\
\text { n (col. \%) }\end{array}$ & $\begin{array}{l}\text { Not used } \\
\text { n (col. \%) }\end{array}$ & OR $(95 \% \mathrm{Cl})$ & $p$-value \\
\hline \multicolumn{5}{|l|}{ Type of Respondent } \\
\hline Adult & $77(67.0)$ & $40(37.7)$ & $3.50(2.02-6.06)$ & $<0.01$ \\
\hline Child Dependent & $38(33.0)$ & $69(63.3)$ & & \\
\hline \multicolumn{5}{|l|}{ Gender } \\
\hline Male & $33(29.2)$ & $44(41.1)$ & $0.59(0.34-1.03)$ & 0.06 \\
\hline Female & $80(70.8)$ & $63(58.9)$ & & \\
\hline \multicolumn{5}{|l|}{ Presence of a Chronic Condition } \\
\hline Any Chronic Condition & 79 (78.2) & 79 (79.8) & $0.91(0.46-1.80)$ & 0.78 \\
\hline No Chronic Condition & $22(21.8)$ & $20(20.2)$ & & \\
\hline \multicolumn{5}{|l|}{ Insurance Status } \\
\hline Medicaid & $38(37.3)$ & $60(58.8)$ & $0.51(0.28-0.94)$ & $<0.01$ \\
\hline Medicare & $15(14.7)$ & $6(5.9)$ & $2.02(0.71-5.78)$ & \\
\hline Uninsured & $7(6.9)$ & $2(2.0)$ & $2.83(0.55-14.54)$ & \\
\hline Private & $42(41.2)$ & $34(33.3)$ & Reference & \\
\hline \multicolumn{5}{|c|}{ Length of Time Visiting a Specific Place for care* } \\
\hline No Regular Doctor/Nurse & $5(4.7)$ & $2(1.9)$ & $0.94(0.14-6.20)$ & $<0.01$ \\
\hline $0-3$ years & $51(47.6)$ & $35(33.3)$ & $0.55(0.20-1.53)$ & \\
\hline 4-7 Years & $35(32.7)$ & $62(59.1)$ & $0.21(0.08-0.59)$ & \\
\hline$>8$ Years & $16(15.0)$ & $6(5.7)$ & Reference & \\
\hline \multicolumn{5}{|c|}{ Length of Time Visiting a Specific Person for care* } \\
\hline No Regular Doctor/Nurse & $13(12.04)$ & $7(6.7)$ & $0.62(0.16-2.43)$ & $<0.01$ \\
\hline $0-3$ years & $49(45.4)$ & $34(32.4)$ & $0.48(0.16-1.45)$ & \\
\hline 4-7 Years & $31(28.7)$ & $59(56.2)$ & $0.18(0.06-0.53)$ & \\
\hline$>8$ Years & 15 (13.9) & $5(4.8)$ & Reference & \\
\hline Measures of access & Used Clinic Median (SD) & Not used Median (SD) & OR $(95 \% \mathrm{Cl})$ & p-value \\
\hline Travel Distance (miles) & $1.31(1.19)$ & $1.21(1.36)$ & $0.91(0.74-1.11)$ & 0.35 \\
\hline BCQ Total Score (0-100) & $73.4(23.1)$ & $55.4(19.3)$ & $1.02(1.01-1.04)$ & $<0.01$ \\
\hline Satisfaction-adjusted distance & $1.22(2.56)$ & $2.49(2.36)$ & $0.81(0.73-0.91)$ & $<0.01$ \\
\hline
\end{tabular}

* BCQ scored on scale 0-100, higher scores indicate greater perceived quality

** Total Score is calculated as an average across all subscales 
Table 4 Multivariable models of health care utilization

\begin{tabular}{|c|c|c|c|c|}
\hline \multirow[t]{2}{*}{ Covariates } & \multicolumn{4}{|c|}{ aOR $\left(95 \%\right.$ Cl) $p$-value ${ }^{* *}$} \\
\hline & \multicolumn{2}{|l|}{ Model 1* (BCQ) } & \multicolumn{2}{|l|}{ Model $2^{*}(S A D)$} \\
\hline \multicolumn{5}{|c|}{ Type of Respondent (vs Child Caregiver) } \\
\hline Adult & $2.21(0.92-5.28)$ & 0.08 & $1.95(0.814-4.68)$ & 0.13 \\
\hline \multicolumn{5}{|c|}{ Insurance (vs. Private) } \\
\hline Medicaid & $0.88((0.36-2.13)$ & 0.63 & $0.79(0.33-1.91)$ & 0.51 \\
\hline Medicare & $1.28(0.40-4.11)$ & 0.72 & $1.23(0.38-3.97)$ & 0.71 \\
\hline Uninsured & $1.19(0.16-8.82)$ & 0.90 & $1.17(0.16-8.81)$ & 0.87 \\
\hline \multicolumn{5}{|c|}{ Length of Visit Place (vs. > 8 years) } \\
\hline No Regular & $1.21(0.06-26.02)$ & 0.61 & $0.91(0.04-18.97)$ & 0.78 \\
\hline $0-3$ years & $0.77(0.08-7.31)$ & 0.99 & $0.75(0.08-6.89)$ & 0.90 \\
\hline $4-7$ years & $0.39(0.04-3.97)$ & 0.19 & $0.38(0.04-3.80)$ & 0.23 \\
\hline \multicolumn{5}{|c|}{ Length of Visit Person (vs. > 8 years) } \\
\hline No Regular & $0.57(0.04-7.99)$ & 0.55 & $0.53(0.04-7.32)$ & 0.56 \\
\hline $0-3$ years & $0.98(0.09-11.02)$ & 0.60 & $0.83(0.08-9.09)$ & 0.74 \\
\hline $4-7$ years & $0.69(0.05-8.74)$ & 0.80 & $0.63(0.05-7.89)$ & 0.78 \\
\hline \multicolumn{5}{|c|}{ Quality of Care Measures } \\
\hline $\mathrm{BCQ}$ & $1.02(1.01-1.04)$ & $<0.01$ & - & - \\
\hline SAD & - & - & $0.85(0.74-0.97)$ & $<0.01$ \\
\hline
\end{tabular}

* Model 1 includes BCQ as the primary exposure variable; Model 2included SAD as the primary exposure variable

${ }^{* *}$ Adjusted for type of respondent, insurance status, and length of time visiting a specific place for care or provider of care

- Variable was not included in the model

segregation rarely include individuals with positive health insight, and likely perpetuate negative experiences or medical mistrust [44, 45]. In New Orleans word of mouth was by far the preferred method to receive information about health care [46]. Pragmatics was another low scoring subscale of the BCQ; survey respondents commonly felt rushed or ignored and that getting seen by a health professional is too time consuming. The benefits of using a clinic close to you may be overshadowed by the quality and timeliness of care delivery. These perceptions of alternative clinics as marginalizing and pragmatically challenging are interesting and they contradict the established literature. It appears that the alternative clinics have yet to fully integrate into the communities they serve.

The mixed-methods predictor, SAD, combines distance and perceptions of quality into one significant predictor of health care utilization. Individuals with a greater perceived distance were significantly less likely to have ever used a clinic than those with a lesser perceived distance. As a measure of access, SAD captures the social and physical barriers to care that stem from residential segregation. More researchers are calling for mixed-method measures that revisit the geographic roles of space and place when studying segregation, health, and accessibility $[35,47]$.
Strengths of the study include a descriptive and analytic analysis of an alternative health system, a patientcentered characterization of marginalized populations, and a comparison of multiple measures of access to care. The study has several limitations. Although we identified various factors associated with utilization, the crosssectional design prevents assessing whether they predict utilization. The use of a convenience sample and the restriction of the sample to New Orleans may limit generalizability of the findings. The high utilization rates, continuity of care, and private insurance coverage may be an artifact of the sampling method in that those attending health fairs may over represent individuals currently engaged in the health care system. Measuring distance to the nearest facility based on home address is another limitation as individuals may use clinics that are more proximal to other locations in their life.

\section{Conclusion}

Community, Mobile, and School-based clinics may be equipped to overcome physical and social barriers to care but have yet to fully integrate into neighborhoods as regular sources of care. Distance is not sufficient to predict the use of a primary care clinic. An individual's perceptions of clinic quality significantly predicted clinic usage, and when combined with distance is a useful indicator of utilization of health care services. Future research regarding access to health services in residentially segregated populations needs to consider the many mechanisms by which segregation can influence health seeking behavior.

\section{Supplementary information}

Supplementary information accompanies this paper at https://doi.org/10. 1186/s12913-019-4743-4.

Additional file 1. Questionnaire. This is a copy of the 57-item questionnaire referenced in the manuscript. It includes the previously cited Barriers to Care Questionnaire (starting at Question \#17) that was developed and validated by Seid et al. [29]. The items prior to Question 17 were designed by the authors of this manuscript.

\section{Abbreviations}

aOR: Adjusted Odds Ratio; BCQ: Barriers to Care Questionnaire;

CHC: Community Health Clinic; Cl: Confidence Interval; GNO) area: Greater New Orleans; MHC: Mobile Health Clinic; OR: Odds Ratio; SAD: Satisfactionadjusted Distance; SBHC: School-based Health Clinic

\section{Acknowledgements}

We are very grateful to the staff for performing the many field interviews and the citizens of New Orleans for providing their thoughts and information.

\section{Authors' contributions}

CR analyzed the data, interpreted the findings, drafted the manuscript, and solicited and made edits. FR conceived the study, assisted in the data interpretation, and provided edits to the manuscript. SS performed

background research, supported data collection, and cleaned the raw data. DW designed the methods, supported data collection, and provided edits to the manuscript. JC conceived the study and provided edits to the 
manuscript. All authors have read and approved the manuscript and the descriptions of their contributions to it.

\section{Funding}

No funding to declare.

\section{Availability of data and materials}

The datasets generated and analyzed during the current study are not publicly available due to identifying information (addresses) and HIPAA requirements.

\section{Ethics approval and consent to participate}

The study was initially approved by the Tulane University Biomedical Institutional Review Board Biomedical committee on July 9, 2014. Written informed was consent was acquired with each participant.

\section{Consent for publication}

Not applicable.

\section{Competing interests}

The authors declare that they have no competing interests.

\section{Author details}

${ }^{1}$ Tulane School Public Health and Tropical Medicine, 1440 Canal St, New Orleans, LA 70112, USA. ${ }^{2}$ Tulane School of Medicine, 1430 Tulane Ave, New Orleans, LA 70112, USA.

Received: 28 February 2019 Accepted: 13 November 2019

Published online: 04 December 2019

\section{References}

1. Franks P, Fiscella K. Primary care physicians and specialists as personal physicians. Health care expenditures and mortality experience. J Fam Pract. 1998;47(2):105-9.

2. Nelson A. Unequal treatment: confronting racial and ethnic disparities in health care. J Natl Med Assoc. 2002;94(8):666.

3. Statistics, N.C.f.H., Health, United States, 2016: With Chartbook on Long-term Trends in Health. 2017

4. Quality, A.f.H.R.a. 2015 National Healthcare Quality and Disparaties Report and 5th anniversary Update on the National Quality Strategy; 2016. p. 16-0015.

5. Medicine, I.o. Health professions education: A bridge to quality. Washington: National Academies Press; 2003.

6. Williams DR, Collins C. Racial residential segregation: a fundamental cause of racial disparities in health. Public Health Rep. 2001:116(5):404

7. White K, Haas JS, Williams DR. Elucidating the role of place in health care disparities: the example of racial/ethnic residential segregation. Health Serv Res. 2012;47(3pt2):1278-99.

8. Gaskin DJ, et al. Residential segregation and the availability of primary care physicians. Health Serv Res. 2012;47(6):2353-76.

9. Gaskin DJ, et al. Segregation and disparities in health services use. Med Care Res Rev. 2009;66(5):578-89.

10. Hargraves $\mathrm{J}$, Hadley J. The contribution of insurance coverage and community resources to reducing racial/ethnic disparities in access to care. Health Serv Res. 2003;38(3):809-29.

11. Fedele DA, et al. Perceived barriers to care in a pediatric medical home: the moderating role of caregiver minority status. Clin Pediatr. 2014;53(4):351-5.

12. Gaskin DJ, et al. Examining racial and ethnic disparities in site of usual source of care. J Natl Med Assoc. 2007;99(1):22.

13. Corbie-Smith $\mathrm{G}$, et al. Influence of usual source of care on differences by race/ethnicity in receipt of preventive services. J Gen Intern Med. 2002;17(6): 458-64.

14. LaVeist TA, Nuru-Jeter A, Jones KE. The association of doctor-patient race concordance with health services utilization. J Public Health Policy. 2003; 24(3-4):312-23.

15. Saha $\mathrm{S}$, et al. Do patients choose physicians of their own race? Health Aff. 2000;19(4):76-83.

16. Fertig AR, Corso PS Balasubramaniam D. Benefits and costs of a free community-based primary care clinic. J Health Hum Serv Adm. Spring. 2012; 34(4):457-70

17. Knopf JA, et al. School-based health centers to advance health equity: a community guide systematic review. Am J Prev Med. 2016;51(1):114-26.
18. Hill CF, Powers BW, Jain Sachin H, Jennifer B, Anthony V, Oriol Nancy E. Mobile Health Clinics in the Era of Reform. Am J Manag Care. 2014;20(3):261-4.

19. Shi $L$, et al. Racial/ethnic and socioeconomic disparities in access to care and quality of care for US health center patients compared with nonhealth center patients. J Ambul Care Manag. 2009;32(4):342-50.

20. Stephanie $W$, et al. The scope and impact of mobile health clinics in the United States: a literature review. Int J Equity Health. 2017;16(1):178.

21. Fussell E, Sastry N, VanLandingham M. Race, socioeconomic status, and return migration to New Orleans after hurricane Katrina. Popul Environ. 2010;31(1-3):20-42.

22. Robert Wood Johnson Foundation, Metro Map: New Orleans, Louisiana Infographic. 2013

23. Reibling N, Rosenthal MB. The (missed) potential of the patient-centered medical home for disparities. Med Care. 2016;54(1):9-16.

24. City of New Orleans Health Department, Greater new Orleans Primary Care Safety Net Access Plan. 2012

25. 504HealthNet, 504Healthnet.org Guide to Community Health Care in Greater New Orleans. 2012

26. Pearce J, Witten K, Bartie P. Neighbourhoods and health: a GIS approach to measuring community resource accessibility. J Epidemiol Community Health. 2006:60(5):389-95.

27. Masoodi M, Rahimzadeh M. Measuring access to urban health services using geographical information system (GIS): a case study of health service management in Bandar Abbas, Iran. Int J Health Policy Manag. 2015;4(7):439.

28. Delamater $\mathrm{PL}$, et al. Measuring geographic access to health care: raster and network-based methods. Int J Health Geogr. 2012;11(1):15.

29. Seid M, et al. Parents' reports of barriers to care for children with special health care needs: development and validation of the barriers to care questionnaire. Ambul Pediatr. 2004;4(4):323-31.

30. Seid M. Barriers to care and primary care for vulnerable children with asthma. Pediatrics. 2008;122(5):994-1002.

31. Seid $M$, et al. Barriers to care questionnaire: reliability, validity, and responsiveness to change among parents of children with asthma. Acad Pediatr. 2009:9(2):106-13.

32. Cordasco KM, et al. English language proficiency and geographical proximity to a safety net clinic as a predictor of health care access. J Immigr Minor Health. 2011;13(2):260-7.

33. Cabrera-Barona P, Blaschke T, Kienberger S. Explaining accessibility and satisfaction related to healthcare: a mixed-methods approach. Soc Indic Res. 2017;133(2):719-39.

34. Hawthorne TL, Kwan MP. Using GIS and perceived distance to understand the unequal geographies of healthcare in lower-income urban neighbourhoods. Geogr J. 2012;178(1):18-30.

35. Merschdorf $\mathrm{H}$, Blaschke T. Revisiting the role of place in geographic information science. ISPRS Int J Geo Inf. 2018;7(9):364.

36. Dewulf $\mathrm{B}$, et al. Correspondence between objective and perceived walking times to urban destinations: influence of physical activity, neighbourhood walkability, and socio-demographics. Int J Health Geogr. 2012;11(1):43

37. Graham B. Population characteristics and geographic coverage of primary care facilities. BMC Health Serv Res. 2018;18(1):398.

38. Hamel L, Firth J, Brodie M. New Orleans ten years after the storm: the Kaiser Family Foundation Katrina survey project. Menlo Park: The Henry J. Kaiser Family Foundation; 2015

39. Comber AJ, Brunsdon C, Radburn R. A spatial analysis of variations in health access: linking geography, socio-economic status and access perceptions. Int J Health Geogr. 2011;10(1):44

40. Yang $\mathrm{S}$, et al. Transportation barriers to accessing health care for urban children. J Health Care Poor Underserved. 2006;17(4):928-43.

41. Syed ST, Gerber BS, Sharp LK. Traveling towards disease: transportation barriers to health care access. J Community Health. 2013;38(5):976-93.

42. The Data Center, Population \& Demographics. 2018: https://www. datacenterresearch.org/.

43. United States Census Bureau, American Community Survey, 2016. 2016: American Fact Finder, <http://factfinder2.census.gov>.

44. Jones M, Pebley AR. Redefining neighborhoods using common destinations: social characteristics of activity spaces and home census tracts compared. Demography. 2014:51(3):727-52.

45. Cornwell EY, Cornwell B. Access to expertise as a form of social capital: an examination of race-and class-based disparities in network ties to experts. Sociol Perspect. 2008;51(4):853-76. 
46. University Medical Center New Orleans. Community Health Needs Assessment LCMC Health: UMCNO; 2018. https://www.umcno.org/aboutumc/community-health-needs-assessment/

47. Kwan M-P. Beyond space (as we knew it): toward temporally integrated geographies of segregation, health, and accessibility: space-time integration in geography and GIScience. Ann Assoc Am Geogr. 2013;103(5):1078-86.

\section{Publisher's Note}

Springer Nature remains neutral with regard to jurisdictional claims in published maps and institutional affiliations.

Ready to submit your research? Choose BMC and benefit from:

- fast, convenient online submission

- thorough peer review by experienced researchers in your field

- rapid publication on acceptance

- support for research data, including large and complex data types

- gold Open Access which fosters wider collaboration and increased citations

- maximum visibility for your research: over $100 \mathrm{M}$ website views per year

At $\mathrm{BMC}$, research is always in progress.

Learn more biomedcentral.com/submissions 